\title{
ACTIVATE: the effect of aclidinium/formoterol on hyperinflation, exercise capacity, and physical activity in patients with COPD
}

This article was published in the following Dove Press journal:

International Journal of COPD

24 August 2017

Number of times this article has been viewed

\author{
Henrik Watz' \\ Thierry Troosters ${ }^{2}$ \\ Kai M Beeh ${ }^{3}$ \\ Judith Garcia-Aymerich ${ }^{4-6}$ \\ Pierluigi Paggiaro ${ }^{7}$ \\ Eduard Molins ${ }^{8}$ \\ Massimo Notari ${ }^{9}$ \\ Antonio Zapata ${ }^{10}$ \\ Diana Jarreta ${ }^{8}$ \\ Esther Garcia Gil ${ }^{8}$ \\ 'Pulmonary Research Institute \\ at LungenClinic Grosshansdorf, \\ Airway Research Center North, \\ German Center for Lung Research, \\ Grosshansdorf, Germany; \\ ${ }^{2}$ Department of Rehabilitation \\ Sciences, Pulmonary Rehabilitation \\ and Respiratory Division, University \\ Hospital Leuven, KU Leuven, \\ Leuven, Belgium; ${ }^{3}$ insaf Respiratory \\ Research Institute $\mathrm{GmbH}$, Wiesbaden, \\ Germany; ${ }^{4}$ Barcelona Institute of \\ Global Health (ISGlobal), Barcelona, \\ Spain; ${ }^{5}$ Universitat Pompeu Fabra \\ (UPF), Barcelona, Spain; ${ }^{6} \mathrm{CIBER}$ \\ Epidemiología y Salud Pública \\ (CIBERESP), Barcelona, Spain; \\ ${ }^{7}$ Department of Surgery, Medicine, \\ Molecular Biology and Critical \\ Care, University of Pisa, Pisa, Italy; \\ ${ }^{8}$ AstraZeneca PLC, Barcelona, \\ Spain; ${ }^{9} \mathrm{~A}$. Menarini Farmaceutica \\ Internazionale S.R.L., Firenze, \\ Italy; ${ }^{10}$ Laboratorios Menarini, S.A., \\ Badalona, Spain
}

Correspondence: Henrik Watz Pulmonary Research Institute at LungenClinic Grosshansdorf, Wöhrendamm 80, 22927

Grosshansdorf, Germany

Tel +49 4I0 2888 II 22

Fax +49 4I0 2888 IIII3

Email h.watz@pulmoresearch.de
Abstract: The Phase IV, 8-week, randomized, double-blind, placebo-controlled ACTIVATE study (NCT02424344) evaluated the effect of aclidinium/formoterol (AB/FF) 400/12 $\mu \mathrm{g}$ twice daily on lung hyperinflation, exercise capacity, and physical activity in patients with moderate-to-severe COPD. Patients received AB/FF $(n=134)$ or placebo $(n=133)(1: 1)$ via the Genuair ${ }^{\mathrm{TM}} /$ Pressair $^{\circledR}$ dry powder inhaler for 8 weeks. From Weeks 5 to 8 , all patients participated in behavioral intervention (BI; daily messages providing step goals). The primary end point was trough functional residual capacity $(\mathrm{FRC})$ at Week 4. Exercise endurance time and physical activity were assessed at Week 4 (pharmacotherapy only) and at Week 8 (8 weeks of pharmacotherapy plus 4 weeks of BI). Other end points included post-dose FRC, residual volume, and inspiratory capacity (IC) at rest and during exercise. After 4 weeks, trough FRC improved with $\mathrm{AB} / \mathrm{FF}$ versus placebo but did not reach significance $(125 \mathrm{~mL} ; P=0.0690)$. However, post-dose FRC, residual volume, and IC at rest improved significantly with $\mathrm{AB} / \mathrm{FF}$ at Week 4 versus placebo (all $P<0.0001$ ). AB/FF significantly improved exercise endurance time and IC at isotime versus placebo at Week $4(P<0.01$ and $P<0.0001$, respectively) and Week 8 $(P<0.05$ and $P<0.0001$, respectively). AB/FF achieved higher step counts $(P<0.01)$ with fewer inactive patients $(P<0.0001)$ at Week 4 versus placebo. Following BI, AB/FF maintained improvements in physical activity at Week 8 and nonsignificant improvements were observed with placebo. AB/FF 400/12 $\mu \mathrm{g}$ demonstrated improvements in lung hyperinflation, exercise capacity, and physical activity versus placebo that were maintained following the addition of BI. A 4-week period of BI might be too short to augment the improvements of physical activity observed with AB/FF.

Keywords: COPD, hyperinflation, aclidinium, formoterol, exercise capacity, physical activity

\section{Plain language summary}

Why was the study done? Patients with COPD often suffer from breathlessness that affects their ability to exercise and go about their daily activities. Being less physically active can lead to an increase in COPD symptoms and a worsening of the patient's COPD, which in turn can result in further reductions in physical activity. Therefore, a key part of COPD management is helping patients to increase their activity levels and to stay active.

What did the researchers do and find? The researchers looked at the effect of aclidinium/ formoterol, a combination of two different inhaled COPD treatments, on lung function and physical activity. Patients taking aclidinium/formoterol for 4 weeks had better lung function than patients taking placebo. Patients taking aclidinium/formoterol could also exercise for longer and increased their daily physical activity by around 730 steps more per day than patients taking placebo. Additionally, when these patients used a mobile phone application to encourage increased activity for a further 4 weeks, improvements in physical activity were maintained. 
What do these results mean? These results suggest that aclidinium/formoterol can improve lung function and physical activity in patients with COPD, particularly when used together with a mobile phone application to encourage and support activity.

\section{Introduction}

COPD is a common, preventable, and treatable disease, characterized by persistent respiratory symptoms and airflow limitation. ${ }^{1}$ Dyspnea on exertion is the primary symptom limiting exercise capacity in patients with COPD, which in turn leads to reduced physical activity in their daily life. ${ }^{2}$ Consequently, as activity-related dyspnea increases, physical activity reduces significantly, not only in patients with severe COPD but also in patients with mild-to-moderate disease. ${ }^{3-5}$ As reduced physical activity in patients with COPD is independently linked to reduced quality of life, ${ }^{6}$ increased hospitalizations, ${ }^{7}$ physical deconditioning, ${ }^{3,8}$ and mortality, ${ }^{9}$ an improvement in physical activity has been identified as potentially disease-modifying, with better long-term outcomes in this debilitating disease. , $^{2,10}$

Lung hyperinflation is thought to present a mechanical link between reduced physical activity and the airflow limitation in patients with COPD. ${ }^{11,12}$ In these patients, physical activity reflects the amount of activity performed in a real-life setting (eg, number of steps taken per day), while exercise capacity is the amount of exercise that patients are capable of doing (ie, functional capacity measured by walking or cycling tests). ${ }^{2,13}$ A number of pharmacological therapies that improve airflow and reduce lung hyperinflation have also been shown to provide improvements in exercise capacity in COPD. ${ }^{11,14-18}$ However, the effects of bronchodilator treatment on physical activity are less clear. ${ }^{17-21}$

Physical inactivity in patients with COPD is not only related to functional limitations but also results from a complex health behavior, which can be changed using behavioral intervention (BI). ${ }^{22}$ Therefore, as well as instigating bronchodilator therapy, consideration should be given to implementing BI, so that patients may be able to make use of the improved exercise tolerance - gained from pharmacotherapy - in daily life.

ACTIVATE (NCT02424344) was a Phase IV, multicenter, 8-week, multiple-dose, randomized, double-blind, placebo-controlled, parallel-group study of aclidinium bromide/formoterol fumarate (AB/FF) 400/12 $\mu \mathrm{g}$ twice daily (b.i.d.). Study objectives were the effect of $A B / F F$ versus placebo on lung hyperinflation (prior to $\mathrm{BI}$ ), exercise endurance time (EET), and physical activity with/without BI in patients with moderate-to-severe COPD.

\section{Materials and methods Study subjects}

The ACTIVATE study was conducted between April 2015 and July 2016 across 26 sites in four countries (Canada, Germany, Hungary, and Spain). Clinical trial registration number: NCT02424344 (ClinicalTrials.gov).

Patients were aged $\geq 40$ years, current or former cigarette smokers with a clinical diagnosis of moderate/severe COPD, with a functional residual capacity (FRC) $\geq 120 \%$ of predicted value, a post-bronchodilator forced expiratory volume in $1 \mathrm{~s}\left(\mathrm{FEV}_{1}\right) \geq 40 \%$ and $<80 \%$ of the predicted value, an $\mathrm{FEV}_{1} /$ forced vital capacity $(\mathrm{FVC})<70 \%$, and a modified Medical Research Council (mMRC) dyspnea scale score of $\geq 2$. Details on inclusion and exclusion criteria are described in the Supplementary material.

Prohibited medication throughout the whole study period (including screening, run-in, and the 8-week treatment period) included any bronchodilator treatment (with the exception of salbutamol used as rescue medication), methylxanthines, and phosphodiesterase type 4 inhibitors. Patients were allowed to continue inhaled corticosteroid therapy, oral or parenteral corticosteroids at a dose equivalent to $10 \mathrm{mg}$ of prednisone per day or $20 \mathrm{mg}$ every other day, and oxygen therapy $<15 \mathrm{~h}$ per day if the administration had been stable for $\geq 4$ weeks.

All patients provided written, informed consent prior to conducting any study-specific procedures. This study was approved by local ethics committees (Table S1) and performed in accordance with the Declaration of Helsinki and Good Clinical Practice Guidelines.

\section{Study design}

In this Phase IV ACTIVATE study, patients were randomized (1:1) to receive $\mathrm{AB} / \mathrm{FF} 400 / 12 \mu \mathrm{g}$ or placebo b.i.d. via a multidose dry powder inhaler (Genuair ${ }^{\mathrm{TM}} /$ Pressair $^{\circledR}$ [Registered trademark of AstraZeneca group of companies; for use within the USA as Pressair and as Genuair within all other licensed territories]). There was an 11-17-day run-in and screening period and an 8-week treatment period, with a follow-up phone call 2 weeks after the final treatment. During the first 4 weeks of the study, patients received pharmacotherapy alone (AB/FF or placebo) and, during the second 4 weeks, BI was added to both treatment arms (Figure 1).

\section{End points and measurements}

The primary efficacy end point was change from baseline in trough FRC after 4 weeks of treatment. The secondary efficacy end points were change from baseline in EET during 

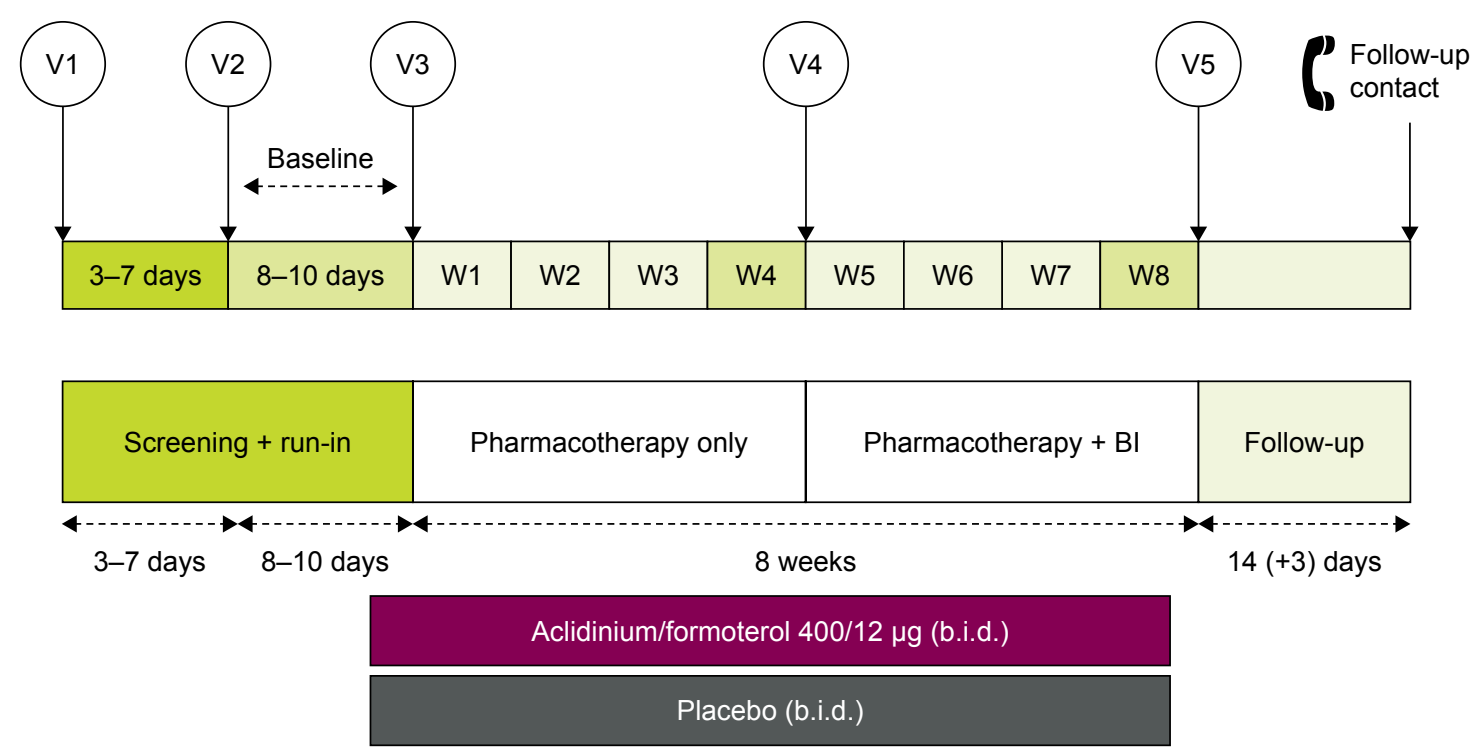

Figure I Study design.

Abbreviations: $\mathrm{BI}$, behavioral intervention; b.i.d., twice daily; $\mathrm{V}$, visit; $\mathrm{W}$, week.

constant work rate cycle ergometry to symptom limitation at $75 \%$ of peak work rate $\left(\mathrm{W}_{\max }\right)$ and the percentage of inactive patients $(<6,000$ steps per day) after 8 weeks of treatment. Additional efficacy end points included the percentage of inactive patients $(<6,000$ steps per day) after 4 weeks of treatment; change from baseline in physical activity parameters after 4 and 8 weeks of treatment; inspiratory capacity (IC) during constant work rate cycle ergometry; change from baseline in Daily PROactive Physical Activity in COPD (D-PPAC) questionnaire scores (total, amount, and difficulty) after 4 and 8 weeks of treatment; and pulmonary function variables after 4 weeks of treatment (pre-dose $\mathrm{FEV}_{1}$ and FVC, post-dose FRC, pre- and post-dose specific airway conductance [sGaw], and residual volume [RV]).

Lung function was assessed using body plethysmography (FRC, RV, and sGaw) and spirometry (FVC and $\mathrm{FEV}_{1}$ ) before exercise, at baseline, and at Week 4, as previously described, ${ }^{18}$ and in accordance with current recommendations. ${ }^{23-25}$ Plethysmography was assessed using MasterScreen Body Plethysmograph (eResearchTechnology [ERT] Inc., Philadelphia, USA, formerly Jaeger/Viasys/ Carefusion), calibrated daily and with monthly, healthy subject quality control tests for consistency. If different plethysmography equipment was used, it was assessed for technical and setup issues prior to the start of the study.

EET was measured using cycle ergometry at constant work rate at $75 \% \mathrm{~W}_{\max }$ at baseline and at $3 \mathrm{~h}$ post-dose at Weeks 4 and 8 , as previously described. ${ }^{18}$ Three minutes of rest was followed by 3 minutes of unloaded cycling, before patients were encouraged to maintain a 50-70 revolutions per minute pedal rate at $75 \% \mathrm{~W}_{\max }$ until symptom limitation. ${ }^{18} \mathrm{IC}$ was measured using a spirometer at rest, during, and at the end of EET assessment. Cycle ergometry was assessed using MasterScreen CPX Ergometry with Ergoline Ergoselect Cycling equipment (ERT Inc., Philadelphia, PA, USA). The spirometry system was calibrated daily and quality control tests were performed in all sites. If different cycle ergometry equipment was used, it was assessed for technical and setup issues prior to the start of the study.

Physical activity levels were measured at baseline, at Week 4, and at Week 8 using an activity monitor (DynaPort MoveMonitor, McRoberts B.V., the Hague, the Netherlands) ${ }^{26}$ for a period of 1 week each, as previously described. ${ }^{22,27}$ Patients wore the accelerometer for $24 \mathrm{~h}$ a day, with the exception of time spent on personal hygiene. ${ }^{4}$ Days were considered valid for the physical activity dataset if $>8 \mathrm{~h}$ of wearing time was recorded on at least 3 days within 1 week (not necessarily consecutive). The average number of steps taken per day, the time in moderate-intensity activities per day ( $>3$ metabolic equivalents as estimated by accelerometer), and the activityrelated energy expenditure were recorded. ${ }^{18}$

Physical activity experience was assessed using the D-PPAC questionnaire, a daily recall, electronic, patientreported outcome (PRO) tool developed by the Innovative Medicines Initiative PROactive project. The D-PPAC was filled out by patients every evening for a week at baseline, at Week 4, and at Week 8. This seven-item PRO measure consists of two physical activity experience domains: amount 
and difficulty. ${ }^{27}$ The amount domain consists of two PRO items plus two activity monitor outputs (steps per day and vector magnitude units per minute); the difficulty domain consists of five PRO items. The total score was calculated as the average of both domain scores. Each domain and the total were scored from 0 to 100 , where higher numbers indicated a better score. A minimum of 3 days of simultaneous monitoring and questionnaire items were needed for a valid assessment.

BI was facilitated using a smartphone application connected to a step counter (Linkcare ${ }^{\circledR}$, Barcelona, Spain), received at Visit 4 of the study, using the goal-setting principles previously described. ${ }^{22} \mathrm{~A}$ day was classified as valid if the patient took $>70$ steps per day. Individualized step goals were set based on the median value of the four most active days in the previous week. If the patient reached their goal, the goal for the following week was either kept the same or increased by 500 steps per day (depending on the patient's preference). If the patient did not reach their goal, the new goal was either unchanged or set to 500 steps more than the median number of steps per day achieved in the previous week (whichever was lowest). Patients who took $<70$ steps a day on $>3$ days kept the same goal as in the previous week. Patients were reminded of their goal in the morning, were able to check their progress throughout the day, and received feedback messages in the evening, as well as receiving motivational and educational messages. Patients received summary feedback at the end of the week.

Treatment-emergent adverse events (TEAEs; including COPD exacerbations), concomitant medication use, and rescue medication use were recorded throughout the study.

\section{Statistical analysis}

The sample size was calculated to provide $\geq 80 \%$ power to detect a significant difference of $-0.200 \mathrm{~L}$ with a common standard deviation (SD) of $0.545 \mathrm{~L}$ in change from baseline in trough FRC at Week 4 of treatment, and $100 \mathrm{~s}$ with a common SD of $260 \mathrm{~s}$ in change from baseline in EET during constant work rate cycle ergometry to symptom limitation at $75 \% \mathrm{~W}_{\max }$ at Week 8 of treatment, when comparing $\mathrm{AB} / \mathrm{FF} 400 / 12 \mu \mathrm{g}$ with placebo, and based on a two-sided test at a significance level of 0.05 . A hierarchical multiplicity approach was used with the following order: change from baseline in FRC for $\mathrm{AB} / \mathrm{FF} 400 / 12 \mu \mathrm{g}$ compared with placebo (primary end point); change from baseline in EET for $\mathrm{AB} / \mathrm{FF} 400 / 12 \mu \mathrm{g}$ compared with placebo; and percentage of inactive patients $(<6,000$ steps per day) for $\mathrm{AB} / \mathrm{FF}$ $400 / 12 \mu \mathrm{g}$ compared with placebo. End points were tested hierarchically, with subsequent end points tested providing the previous end point achieved a 5\% significance level. The primary end point was analyzed using analysis of covariance (ANCOVA) models, and the secondary and additional end points were analyzed using mixed models for repeated measures. Detailed statistical methods are provided in the Supplementary material.

The safety population (used for adverse event [AE] analyses) and the intent-to-treat (ITT) population (used for efficacy analyses) were both defined as all randomized patients who took at least one dose of study medication.

\section{Results \\ Study population}

Of the 335 patients screened, 267 were randomized $(\mathrm{AB} / \mathrm{FF}$, $\mathrm{n}=134$; placebo, $\mathrm{n}=133)$ and 250 completed the study $(\mathrm{AB} / \mathrm{FF}$, $n=127$; placebo, $n=123$ ) (Figure 2). Patient demographics and characteristics were similar between groups (Table 1).

\section{Efficacy}

\section{Lung function}

Patients receiving $\mathrm{AB} / \mathrm{FF}$ demonstrated a greater reduction in adjusted mean change from baseline versus placebo in trough FRC at Week 4, but this did not reach statistical significance $(0.125 \mathrm{~L} ; P=0.069$; Figure 3$)$. As this primary end point did not achieve statistical significance, all $P$-values for secondary and additional end points are nominal and no formal statistical inference can be drawn.

Post-hoc analysis of change from baseline versus placebo in trough FRC, based on a nonparametric Wilcoxon-Mann-Whitney test, showed a statistically significant difference between $\mathrm{AB} / \mathrm{FF}$ and placebo $(P=0.0034)$. Estimated asymptotic shift (Hodges-Lehmann) was $-0.170 \mathrm{~L}$ (95\% CI: $-0.300 \mathrm{~L},-0.060 \mathrm{~L}$ ). In addition, the post-hoc outlier and influential data analysis identified four outlying patients: two in the $\mathrm{AB} / \mathrm{FF}$ treatment group and two in the placebo group. Once these patients were excluded from the ITT ANCOVA analysis, a statistically significant reduction of $0.196 \mathrm{~L}$ ( $P=0.0010)$ between $\mathrm{AB} / \mathrm{FF}$ and placebo was demonstrated.

Lung hyperinflation and other pulmonary function measurements are reported in Table 2. Of note, post-dose lung hyperinflation measurements showed significant improvements in change from baseline in FRC, RV, IC, and sGaw at Week 4 with $\mathrm{AB} / \mathrm{FF}$, compared with placebo $(0.366 \mathrm{~L}, 0.465 \mathrm{~L}$, $0.293 \mathrm{~L}$, and $0.341 \mathrm{~s}^{-1} \mathrm{kPa}^{-1}$ respectively; all $P<0.0001$; Table 2). Furthermore, a significant improvement in adjusted mean change from baseline in pre-dose (trough) $\mathrm{FEV}_{1}$ was found for $\mathrm{AB} / \mathrm{FF}$ compared with placebo at Week 4 ( $0.209 \mathrm{~L}$; $P<0.0001$; Table 2). 


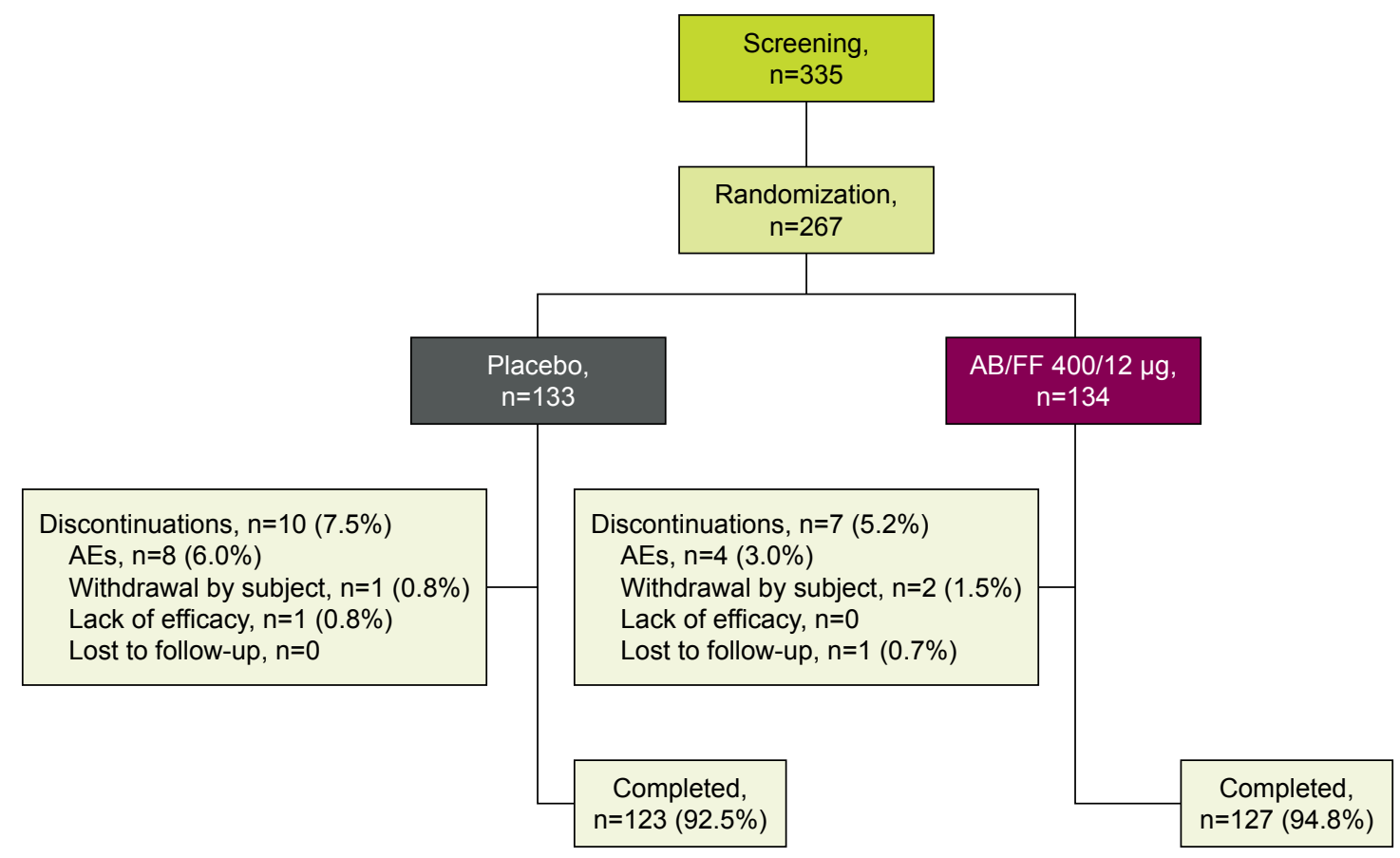

Figure 2 Patient flow.

Abbreviations: $A B$, aclidinium bromide; $A E$, adverse event; $F F$, formoterol fumarate.

\section{Exercise capacity}

Compared with placebo, patients treated with $\mathrm{AB} / \mathrm{FF}$ had greater improvements from baseline in exercise capacity during constant cycle ergometry at $75 \% \mathrm{~W}_{\max }$, as demonstrated by a longer adjusted mean change from baseline in EET at both Week $4(58.9 \mathrm{~s} ; P=0.0089)$ and Week $8(55.2 \mathrm{~s}$; $P=0.0292$; Figure 4A). Additionally, improvements in IC during exercise were also observed at both Weeks 4 and 8 , with a treatment difference in IC at isotime of $0.246 \mathrm{~L}$ and $0.226 \mathrm{~L}$, and at the end of exercise of $0.218 \mathrm{~L}$ and $0.194 \mathrm{~L}$ (all $P<0.0001$ ) (Figure 4B).

\section{Physical activity}

Mean daily wearing time for activity monitors was around $23 \mathrm{~h}$ throughout the study ( $23 \mathrm{~h} 27 \mathrm{~min}$ at baseline, $23 \mathrm{~h}$ $18 \mathrm{~min}$ at Week 4, and $22 \mathrm{~h} 57 \mathrm{~min}$ at Week 8). After 4 weeks of treatment, the percentage of inactive patients on $\mathrm{AB} / \mathrm{FF}$ was significantly lower compared with placebo (odds ratio [OR], $0.27 ; P<0.0001$; Figure 5A). Patients receiving AB/FF showed significant improvements in the number of steps per day (621; standard error [SE], 167) compared with a decrease of 110 (SE, 167) steps per day in placebo (treatment difference of 731 steps per day; $P=0.0016$; Figure $5 B)$. Significant treatment differences were also observed for daily duration of at least moderate-intensity activities and activity-related energy expenditure (Figures S1 and S2). During the last 4 weeks of the study (from Week 5 to Week 8), BI maintained the improvements achieved in the number of steps per day after 4 weeks of $\mathrm{AB} / \mathrm{FF}$ treatment (increase of 32 steps per day from Week 4 to Week 8). In contrast, patients receiving placebo had an improvement of 252 steps per day from Week 4 to Week 8 , corresponding to a numerical difference of 510 steps per day ( $P=0.1588$; Figure 5B) for $\mathrm{AB} / \mathrm{FF}$ compared with placebo, and a numerical difference in the percentage of inactive patients in favor of the $\mathrm{AB} / \mathrm{FF}$ group (OR, $0.44 ; P=0.1134$; Figure $5 \mathrm{~A})$.

The D-PPAC questionnaire total score, amount, and difficulty domains improved significantly in the $\mathrm{AB} / \mathrm{FF}$ group versus placebo at Week $4(P<0.03$; Figure 6). At Week 8 , $\mathrm{AB} / \mathrm{FF}$ maintained the improvements seen after 4 weeks; however, the differences versus placebo were not statistically significant (Figure 6).

\section{Safety}

The number of TEAEs was comparable between $\mathrm{AB} / \mathrm{FF}$ and placebo ( $42.5 \%$ and $45.1 \%$, respectively), with low numbers of serious AEs and AEs leading to discontinuation in both treatment groups (AB/FF: $1.5 \%$ and $3.0 \%$; placebo: $2.3 \%$ and $4.5 \%$, respectively). Nasopharyngitis (AB/FF, 10.4\%; placebo, $9.8 \%$ ) and headache (AB/FF, 3.0\%; placebo, 9.0\%) were the only events reported by $>5 \%$ of patients.

\section{Discussion}

In the ACTIVATE study, treatment with AB/FF 400/12 $\mu \mathrm{g}$ significantly improved lung hyperinflation in patients with 
Table I Baseline demographics and clinical characteristics (ITT population)

\begin{tabular}{|c|c|c|c|}
\hline & $\begin{array}{l}\text { Placebo } \\
(n=133)\end{array}$ & $\begin{array}{l}\text { AB/FF } \\
400 / 12 \mu g \\
(n=134)\end{array}$ & $\begin{array}{l}\text { Total } \\
(n=267)\end{array}$ \\
\hline Age, mean years (SD) & $62.1(7.7)$ & $62.6(7.9)$ & $62.3(7.8)$ \\
\hline Male, \% & 59.4 & 60.5 & 59.9 \\
\hline Current smoker, \% & 62.4 & 63.4 & 62.9 \\
\hline $\begin{array}{l}\text { Smoking history, mean } \\
\text { pack-years (SD) }\end{array}$ & $46.4(21.6)$ & $48.4(24.0)$ & $47.4(22.8)$ \\
\hline \multicolumn{4}{|l|}{ COPD severity, \% } \\
\hline Moderate & 82.0 & 76.7 & 79.3 \\
\hline Severe & 18.0 & 23.3 & 20.7 \\
\hline $\begin{array}{l}\text { Post-bronchodilator FEV } \% \\
\text { predicted, mean (SD) }\end{array}$ & $61.0(10.7)$ & $60.3(10.7)$ & $60.7(10.7)$ \\
\hline FRC \% predicted, mean (SD) & $148.0(26.2)$ & I5I.4 (27.7) & | 49.7 (27.0) \\
\hline \multicolumn{4}{|l|}{ mMRC scale, \% } \\
\hline Grade 2 & 91.7 & 91.0 & 91.4 \\
\hline Grade 3 & 8.3 & 9.0 & 8.6 \\
\hline \multicolumn{4}{|l|}{ Prior medication } \\
\hline LAMA, n (\%) & $23(17.3)$ & $24(17.9)$ & $47(17.6)$ \\
\hline LABA, n (\%) & II (8.3) & $16(11.9)$ & $27(10.1)$ \\
\hline ICS, n (\%) & $8(6.0)$ & $2(1.5)$ & $10(3.8)$ \\
\hline LAMA/LABA, n (\%) & $40(30.1)$ & $34(25.4)$ & $74(27.7)$ \\
\hline LABA/ICS, n (\%) & $14(10.5)$ & $17(12.7)$ & $31(11.6)$ \\
\hline LAMA/ICS, n (\%) & $\mathrm{I}(0.8)$ & $2(1.5)$ & $3(1.1)$ \\
\hline LAMA/LABA/ICS, n (\%) & $5(3.8)$ & II (8.2) & $16(6.0)$ \\
\hline $\begin{array}{l}\text { Number of exacerbations in } \\
\text { previous year, mean (SD) }\end{array}$ & $0.4(1.0)$ & $0.3(0.5)$ & $0.3(0.8)$ \\
\hline Mean endurance time, s (SD) & $\begin{array}{l}456.9 \\
(181.7)\end{array}$ & $\begin{array}{l}455.8 \\
(184.9)\end{array}$ & $\begin{array}{l}456.3 \\
(183.0)\end{array}$ \\
\hline Inactive patients, ${ }^{a} \%$ & 48.1 & 54.6 & 51.4 \\
\hline $\begin{array}{l}\text { Mean number of steps per } \\
\text { day (SD) }\end{array}$ & $\begin{array}{l}6,186.9 \\
(3,066.5)\end{array}$ & $\begin{array}{l}6,368.4 \\
(3,398.6)\end{array}$ & $\begin{array}{l}6,278.0 \\
(3,232.5)\end{array}$ \\
\hline \multicolumn{4}{|l|}{ D-PPAC } \\
\hline Total score, mean (SD) & $62.5(9.7)$ & $62.5(10.1)$ & $62.5(9.9)$ \\
\hline Difficulty domain, mean (SD) & $70.8(13.9)$ & $69.6(13.6)$ & $70.1(13.7)$ \\
\hline Amount domain, mean (SD) & $53.7(14.2)$ & $54.5(13.0)$ & $54.1(13.5)$ \\
\hline
\end{tabular}

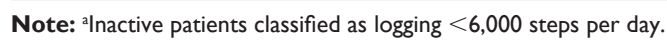

Abbreviations: $A B$, aclidinium bromide; D-PPAC, Daily PROactive Physical Activity in COPD; $\mathrm{FEV}_{1}$, forced expiratory volume in I s; FF, formoterol fumarate; FRC, functional residual capacity; ICS, inhaled corticosteroids; ITT, intent-to-treat; LABA, long-acting $\beta_{2}$-agonist; LAMA, long-acting muscarinic antagonist; mMRC, modified Medical Research Council; SD, standard deviation.

moderate-to-severe COPD (excluding trough FRC in the primary analysis). This improvement in lung hyperinflation was associated with improved exercise capacity and objectively measured physical activity and physical activity experience. These observations support the important role of lung deflation by bronchodilators in reducing hyperinflation-caused dyspnea during physical activity in patients with COPD.

The significant improvements in lung hyperinflation and exercise capacity observed with $\mathrm{AB} / \mathrm{FF}$ versus placebo are comparable in magnitude with those reported in a previous study with aclidinium $400 \mu \mathrm{g}$ alone,${ }^{18}$ while the improvements

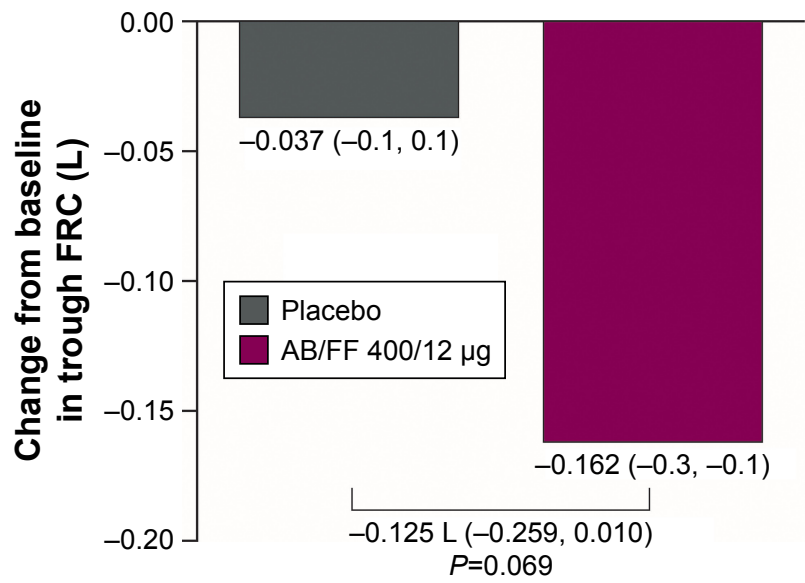

Figure 3 Change from baseline in trough FRC at Week 4 (ITT population). Note: Data are LSMs $(95 \% \mathrm{Cl})$.

Abbreviations: $\mathrm{AB}$, aclidinium bromide; $\mathrm{Cl}$, confidence interval; $\mathrm{FF}$, formoterol fumarate; FRC, functional residual capacity; ITT, intent-to-treat; LSM, least squares mean.

in steps per day ( $\sim 10 \%$ increase) appear more pronounced than those seen with aclidinium alone $(\sim 6 \%$ increase $) .{ }^{18}$ Additionally, the improvement in EET of $\sim 1$ minute with $\mathrm{AB} / \mathrm{FF}$ is similar to previous studies evaluating the effect of dual bronchodilation on exercise capacity ${ }^{28,29}$ and is in the range considered clinically significant. ${ }^{30,31}$

The maximum treatment difference in physical activity between $\mathrm{AB} / \mathrm{FF}$ and placebo was observed during the first 4 weeks of treatment, prior to BI, with no substantial further increase of physical activity in patients on active treatment during BI. In patients receiving placebo, BI led to an increase in physical activity, although this was nonsignificant.

Table 2 Lung function at Week 4 (ITT population)

\begin{tabular}{|c|c|c|c|}
\hline & $\begin{array}{l}\text { Placebo } \\
(n=133)\end{array}$ & $\begin{array}{l}\text { AB/FF } \\
400 / 12 \mu \mathrm{g} \\
(n=134)\end{array}$ & $\mathbf{S}$ \\
\hline \multicolumn{4}{|c|}{$\begin{array}{l}\text { Change from baseline in post-dose lung function parameters } \\
\text { at Week } 4\end{array}$} \\
\hline $\mathrm{FRC},{ }^{\mathrm{a}} \mathrm{L}$ & -0.146 & $-0.5 \mathrm{II}$ & $-0.366 * * * *(-0.5 \mathrm{I} 5,-0.2 \mathrm{I}$ \\
\hline $\mathrm{RV},{ }^{\mathrm{a}} \mathrm{L}$ & -0.094 & -0.559 & $-0.465^{* * * *}(-0.649,-0.28 \mathrm{I})$ \\
\hline $\mathrm{IC}^{\mathrm{b}}$ at rest, $\mathrm{L}$ & $-0.08 \mathrm{I}$ & 0.212 & $0.293 * * * *(0$. \\
\hline sGaw, ${ }^{\mathrm{a}} \mathrm{s}^{-1} \mathrm{kPa}^{-1}$ & 0.014 & 0.356 & 0.34 I $* * * * *(0.245,0.437)$ \\
\hline \multicolumn{4}{|c|}{$\begin{array}{l}\text { Change from baseline in pre-dose lung function parameters } \\
\text { at Week } 4\end{array}$} \\
\hline $\mathrm{FEV}_{1}, \mathrm{~L}$ & -0.051 & 0.159 & $0.209 * * * *(0.161,0.258)$ \\
\hline FVC, L & -0.051 & 0.208 & $0.259 * * * * *(0.182,0.337)$ \\
\hline$R V, L$ & -0.051 & -0.195 & $-0.144 \S(-0.292,0.004)$ \\
\hline $\mathrm{sGaw}, \mathrm{s}^{-1} \mathrm{kPa}^{-1}$ & -0.015 & 0.135 & $0.150 * * * *(0.095,0.205)$ \\
\hline \multicolumn{4}{|c|}{$\begin{array}{l}\text { Notes: } * * * * P<0.000 \text { I versus placebo; }{ }^{\circledR P}=0.0558 \text { versus placebo. }{ }^{a} \text { Measured via } \\
\text { body plethysmography } 2 \mathrm{~h} \text { post-dose; 'Measured via spirometry } 3 \mathrm{~h} \text { post-dose. } \\
\text { Abbreviations: } \mathrm{AB} \text {, aclidinium bromide; } \mathrm{Cl} \text {, confidence interval; } \mathrm{FEV}{ }_{1} \text {, forced } \\
\text { expiratory volume in I s; } \mathrm{FF} \text {, formoterol fumarate; } \mathrm{FRC} \text {, functional residual capacity; } \\
\mathrm{FVC} \text {, forced vital capacity; IC, inspiratory capacity; ITT, intent-to-treat; LSM, least } \\
\text { squares mean; } \mathrm{RV} \text {, residual volume; sGaw, specific airway conductance. }\end{array}$} \\
\hline
\end{tabular}
squares mean; RV, residual volume; sGaw, specific airway conductance. 
A

Placebo $\square$ AB/FF 400/12 $\mu \mathrm{g}$

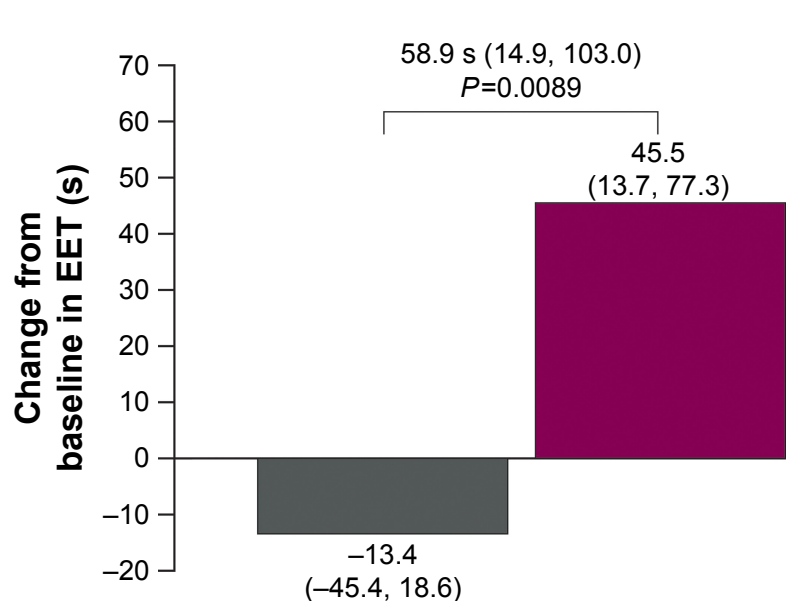

Week 4

Pharmacotherapy only

B

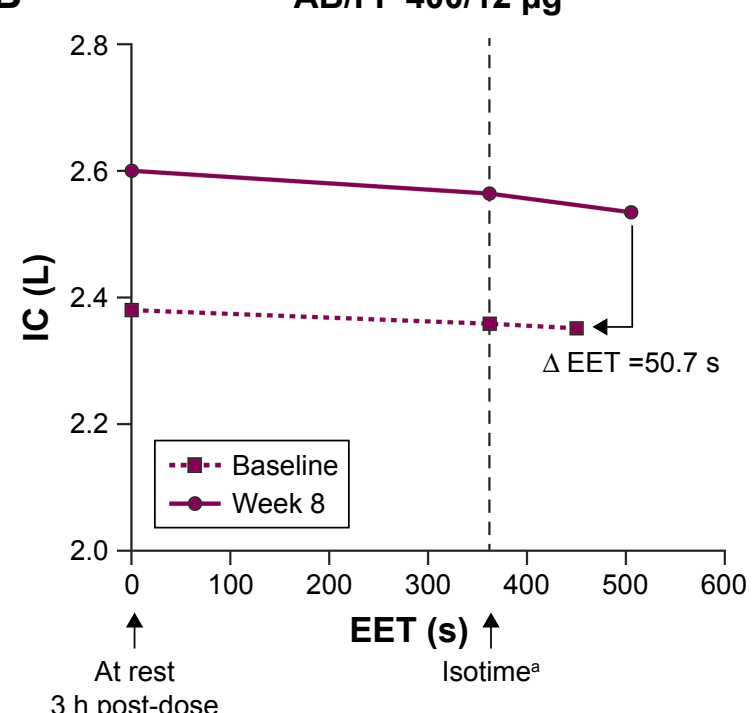

$55.2 \mathrm{~s}(5.6,104.8)$ $P=0.0292$

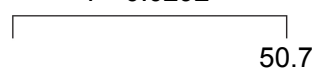

$(15.0,86.3)$
$-4.6$

$(-40.4,31.3)$

Week 8

Pharmacotherapy + BI

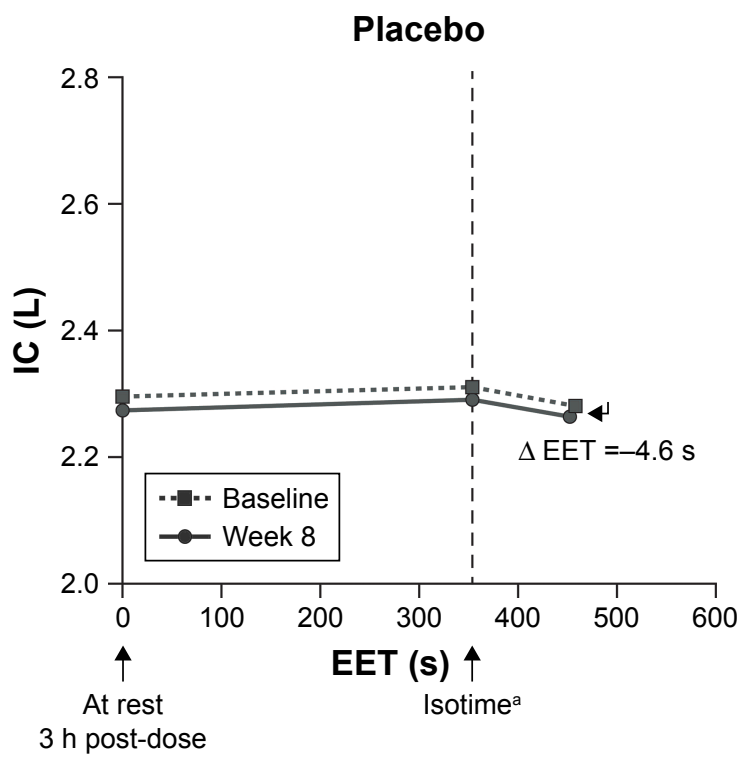

\begin{tabular}{|l|l|l|l|}
\hline IC at Week 8 & Rest & Isotime $^{\mathbf{a}}$ & End of exercise \\
\hline Treatment difference & $0.244(0.159,0.329)$ & $0.226(0.149,0.304)$ & $0.194(0.115,0.272)$ \\
\hline $\begin{array}{l}\text { AB/FF 400/12 } \mathrm{mg} \text { versus } \\
\text { placebo, } \mathrm{L}(95 \% \mathrm{Cl})\end{array}$ & $P<0.0001$ & $P<0.0001$ & $P<0.0001$ \\
\hline
\end{tabular}

Figure 4 Change from baseline in (A) EET at Week 4 (after pharmacotherapy only) and at Week 8 (after pharmacotherapy and BI), and (B) IC during constant work rate cycle ergometry at Week 8 (ITT population).

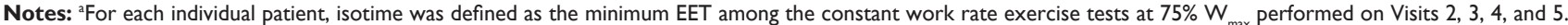
Data are LSMs $(95 \% \mathrm{Cl})$.

Abbreviations: $\mathrm{AB}$, aclidinium bromide; $\mathrm{BI}$, behavioral intervention; $\mathrm{Cl}$, confidence interval; $\mathrm{EET}$, exercise endurance time; $\mathrm{FF}$, formoterol fumarate; $\mathrm{IC}$, inspiratory capacity; ITT, intent-to-treat; LSM, least squares mean; $\mathrm{W}_{\max }$, peak work rate.

This numerical increase is in line with previous studies that have observed short-term increases in step counts as a consequence of $\mathrm{BI}$ in patients with no changes in pharmacotherapy. $22,32,33$ It was unexpected that patients receiving $\mathrm{AB} / \mathrm{FF}$ had no additional improvement in physical activity after participating in the BI program. A potential explanation for the lack of further improvement in physical activity during $\mathrm{BI}$ in patients treated with $\mathrm{AB} / \mathrm{FF}$ could be that the patients had already improved their physical activity by around $10 \%$ compared to baseline, which is clearly in the upper range of 


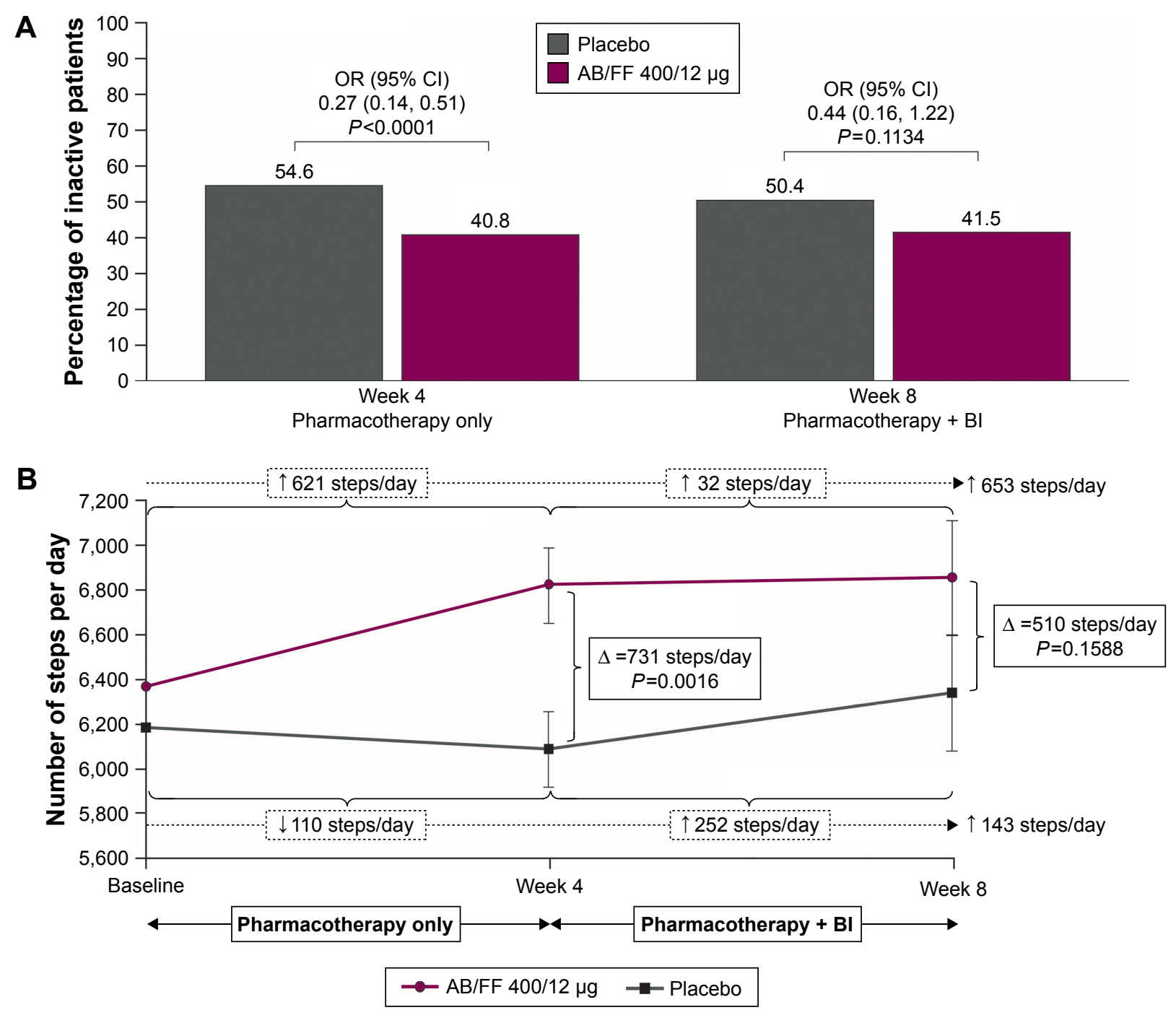

Figure 5 (A) Percentage of inactive patients ( $<6,000$ steps per day) over 8 weeks (ITT population) and (B) absolute number of steps per day over 8 weeks (ITT population). Note: Steps per day data are LSM \pm SE.

Abbreviations: $\mathrm{AB}$, aclidinium bromide; $\mathrm{BI}$, behavioral intervention; $\mathrm{Cl}$, confidence interval; FF, formoterol fumarate; ITT, intent-to-treat; LSM, least squares mean; OR, odds ratio; SE, standard error.

improvements observed with bronchodilation in similar study populations and settings. ${ }^{18-20}$ Additionally, in a population that has already made substantial improvements in physical activity following effective pharmacotherapy, 4 weeks of BI may not have been sufficient time to foster additional improvements. For example, a study into effectiveness of a 12-week semi-automated telecoaching intervention reported that in a patient population with an $\mathrm{mMRC} \geq 2$, patients increased their activity by 560 steps per day over a 3-month period, which is of a similar magnitude observed for the active treatment group in this 8 -week study. ${ }^{22}$ Indeed, modifying behavior is a much more complex process than the provision of drug treatment for patients. ${ }^{34}$ Importantly, the initial increase in physical activity was not lost in patients receiving $\mathrm{AB} / \mathrm{FF}$ when the $\mathrm{BI}$ was added, which is encouraging.
In addition, this study provides a new insight into the patient-centered concept of physical activity experience. Notably, patients treated with $\mathrm{AB} / \mathrm{FF}$ reported less difficulty with physical activity, an effect not observed with BI only. Taken together with the improved levels of physical activity observed with $\mathrm{AB} / \mathrm{FF}$, the results suggest that an increase in physical activity due to bronchodilation does not result in an unpleasant, burdensome experience for patients when increasing their activity levels. This is potentially highly relevant information for health care providers trying to motivate patients to adopt and maintain a more active lifestyle.

Whilst the improvements in exercise capacity and lung function observed in patients receiving $\mathrm{AB} / \mathrm{FF}$ are in the range of what is considered to be clinically meaningful, ${ }^{30,31}$ it is more challenging to appraise whether the improvements 


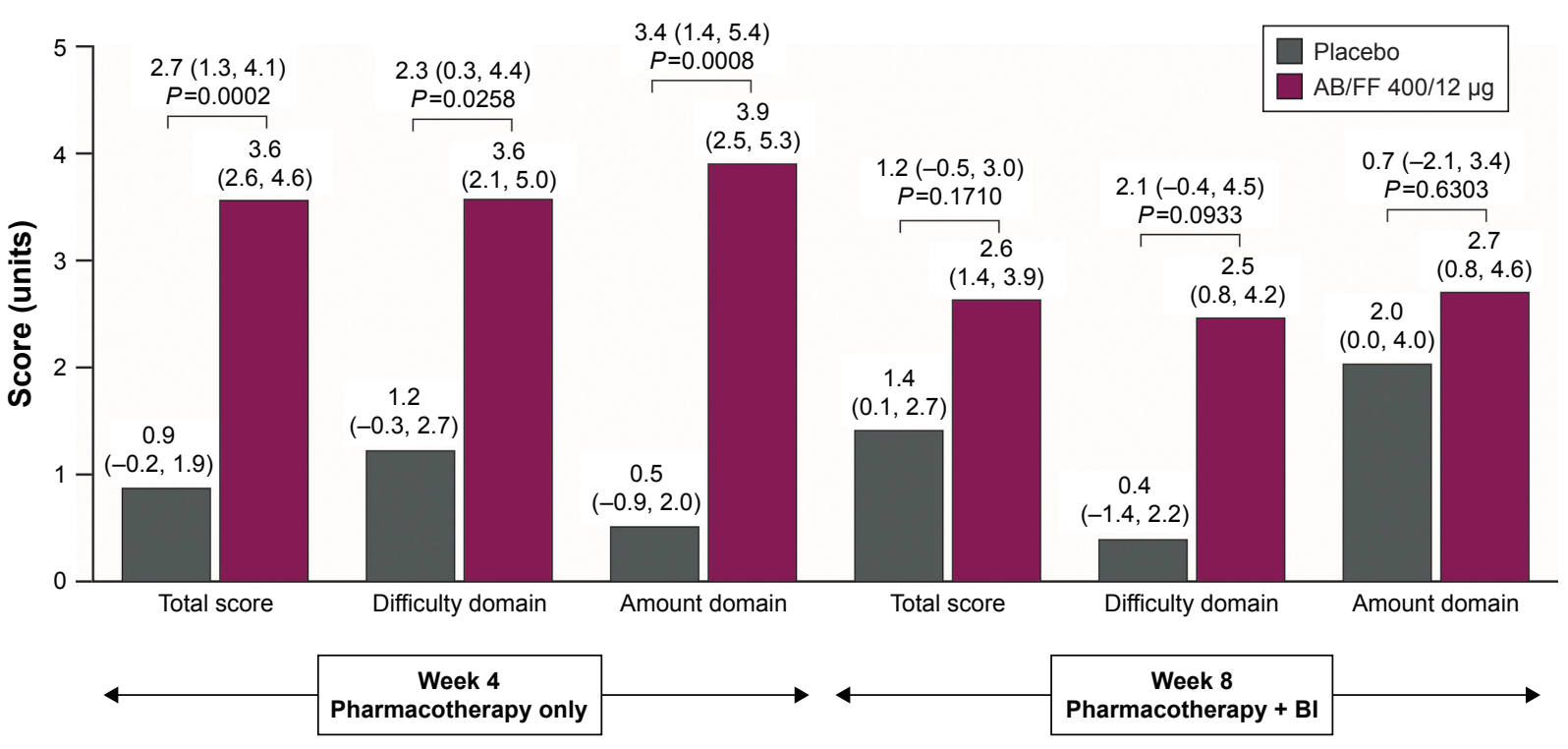

Figure 6 Change from baseline in D-PPAC total score and amount and difficulty domains at Weeks 4 and 8 (ITT population).

Note: Data are LSMs $(95 \% \mathrm{Cl})$.

Abbreviations: AB, aclidinium bromide; $\mathrm{BI}$, behavioral intervention; $\mathrm{Cl}$, confidence interval; D-PPAC, Daily PROactive Physical in COPD; FF, formoterol fumarate; ITT, intent-to-treat; LSM, least squares mean.

in physical activity are clinically meaningful as limited data are available. It is known from observational studies that the number of steps in patients with COPD is independently related to hospitalizations and mortality. ${ }^{7,9}$ An interventional study showed that following 3 months of pulmonary rehabilitation, the risk of hospitalization was lower in those patients who had increased their daily physical activity by more than 600 steps per day. ${ }^{35}$ Likewise, following 4 months of an internet-mediated, pedometer-based program, an increase of 780 steps per day was associated with significant improvements in health status in patients with COPD. ${ }^{32}$ Thus the combination of bronchodilation with non-pharmacological interventions, such as behavior modification programs to increase physical activity or pulmonary rehabilitation, may represent an important therapeutic approach to modifying pathophysiological characteristics and improving long-term outcomes in COPD. . $^{2,10,13,36}$

When considering the design of the ACTIVATE study and any impact this may have had on the results, it should be noted that statistical significance for the primary end point (trough FRC) was reached only after the use of a nonparametric test or after excluding four potential outliers (the sample size was too small to overcome random error in the presence of these extreme outliers). It was unexpected that the improvements in trough FRC did not reach statistical significance, given that previous evidence showed that aclidinium $400 \mu \mathrm{g}$ improved trough FRC in patients with moderate-to-severe COPD, ${ }^{18}$ in addition to improvements in other lung hyperinflation end points both in patients with moderate-to-severe $\mathrm{COPD}^{18}$ and in patients with severe-tovery severe COPD. ${ }^{37}$ However, when considered collectively with the post-dose data, this post-hoc analysis supports the conclusion that $\mathrm{AB} / \mathrm{FF}$ significantly reduced lung hyperinflation. In addition to this, the 2-month study period of ACTIVATE is too short to show long-term treatment effects on physical activity, considering that it can be challenging to encourage long-term changes in physical activity in patients with $\mathrm{COPD}^{38}$ and that data for long-term improvements of physical activity by bronchodilators are lacking.

However, the major strength of the ACTIVATE study lies in the examination of the effects of multimodal intervention (ie, dual bronchodilation plus BI) to encourage patients to increase their daily physical activity levels and the assessment of the effects of using both an electronic activity monitor and PROs in the form of the D-PPAC questionnaire. Furthermore, by introducing $\mathrm{BI}$ in the second half of the ACTIVATE study period, it was possible to assess the effects of pharmacotherapy and $\mathrm{BI}$ alone.

In conclusion, $\mathrm{AB} / \mathrm{FF} 400 / 12 \mu \mathrm{g}$ demonstrated improvements in hyperinflation, exercise tolerance, and physical activity versus placebo. In the short term, BI did not further augment the improvements observed with $\mathrm{AB} / \mathrm{FF}$.

\section{Acknowledgments}

The authors would like to thank all of the patients and their families, and the team of investigators, research nurses, 
and operations staff involved in this study. Specifically, the authors would like to thank Miguel Moya, Idoia Herrero, and Natalia Calderon of AstraZeneca, and Remei Artigas Feliu and Giandomenico Manna of Menarini. The authors would also like to thank Siobhán Hoy and Richard Knight, PhD, of Complete Medical Communications, Macclesfield, UK, for providing medical writing support, which was funded by AstraZeneca in accordance with Good Publication Practice (GPP3) guidelines. This study was sponsored by Menarini Group through its affiliate Berlin-Chemie and AstraZeneca. Menarini Group and AstraZeneca were involved in the study design, collection, analysis, interpretation of data, and development of this manuscript. Menarini Group and AstraZeneca were also involved in the review of the manuscript. The decision to submit the manuscript for publication was made by the authors.

\section{Disclosure}

Henrik Watz has received honoraria for consultancies, lectures, and travel support to attend scientific congresses from Almirall, AstraZeneca, Berlin-Chemie, Boehringer Ingelheim, Chiesi, GlaxoSmithKline, Novartis, and Takeda. His institution received investigator fees for participation in clinical trials from Almirall, AstraZeneca, Bayer Health Care, Berlin-Chemie, Boehringer Ingelheim, Chiesi, GlaxoSmithKline, Novartis, Sanofi Aventis, Roche, and Takeda. Thierry Troosters has received grants from the Innovative Medicines Initiative Joint Undertaking and speaker fees from Boehringer Ingelheim, AstraZeneca, and GlaxoSmithKline. Kai M Beeh's institution has received compensation for organizing or participating in advisory boards (from Almirall Hermal, Cytos, Chiesi, Boehringer Ingelheim, AstraZeneca, Mundipharma, Novartis, and Teva), has participated in scientific meetings or courses (supported by Almirall Hermal, AstraZeneca, Boehringer Ingelheim, Mundipharma, Novartis, Pfizer, and Teva) in the past 3 years, has received consulting fees (from Ablynx, Apellis Pharmaceuticals, Sterna GmbH, Chiesi, and Cytos), and has received compensation for the design, performance, or participation in single or multicenter clinical trials in the past 3 years (from Almirall, AstraZeneca, Boehringer Ingelheim, GlaxoSmithKline, Infinity, Mundipharma, Novartis, Pfizer, Revotar Biopharmaceuticals, Sterna GmbH, Teva, and Zentiva). Judith Garcia-Aymerich's institution has received consulting and lecture fees from AstraZeneca, and lecture fees from Esteve. Pierluigi Paggiaro is on the AstraZeneca, Boehringer Ingelheim, Chiesi, GlaxoSmithKline, and Novartis boards and has received lecture fees from AstraZeneca, Boehringer Ingelheim, Chiesi, GlaxoSmithKline, Laboratori Guidotti, Menarini, Mundipharma, Novartis, Sanofi, and Teva. Eduard Molins, Diana Jarreta, and Esther Garcia Gil are employees of AstraZeneca PLC, Barcelona, Spain. Massimo Notari is an employee of A. Menarini Farmaceutica Internazionale S.R.L., Firenze, Italy. Antonio Zapata is an employee of Laboratorios Menarini, S.A., Badalona, Spain. The authors report no other conflicts of interest in this work.

\section{References}

1. Vogelmeier CF, Criner GJ, Martinez FJ, et al. Global strategy for the diagnosis, management, and prevention of chronic obstructive lung disease 2017 report: GOLD executive summary. Eur Respir J. 2017;49(3): 1700214 .

2. Watz H, Pitta F, Rochester CL, et al. An official European Respiratory Society statement on physical activity in COPD. Eur Respir J. 2014; 44(6):1521-1537.

3. Shrikrishna D, Patel M, Tanner RJ, et al. Quadriceps wasting and physical inactivity in patients with COPD. Eur Respir J. 2012;40(5): $1115-1122$.

4. Watz H, Waschki B, Meyer T, Magnussen H. Physical activity in patients with COPD. Eur Respir J. 2009;33(2):262-272.

5. van Remoortel H, Hornikx M, Demeyer H, et al. Daily physical activity in subjects with newly diagnosed COPD. Thorax. 2013;68(10): 962-963.

6. Waschki B, Spruit MA, Watz H, et al. Physical activity monitoring in COPD: compliance and associations with clinical characteristics in a multicenter study. Respir Med. 2012;106(4):522-530.

7. Donaire-Gonzalez D, Gimeno-Santos E, Balcells E, et al. Benefits of physical activity on COPD hospitalisation depend on intensity. Eur Respir J. 2015;46(5):1281-1289.

8. Waschki B, Kirsten AM, Holz O, et al. Disease progression and changes in physical activity in patients with chronic obstructive pulmonary disease. Am J Respir Crit Care Med. 2015;192(3):295-306.

9. Waschki B, Kirsten A, Holz O, et al. Physical activity is the strongest predictor of all-cause mortality in patients with COPD: a prospective cohort study. Chest. 2011;140(2):331-342.

10. Troosters T, van der Molen T, Polkey M, et al. Improving physical activity in COPD: towards a new paradigm. Respir Res. 2013;14:115.

11. Rossi A, Aisanov Z, Avdeev S, et al. Mechanisms, assessment and therapeutic implications of lung hyperinflation in COPD. Respir Med. 2015;109(7):785-802.

12. Thomas M, Decramer M, O'Donnell DE. No room to breathe: the importance of lung hyperinflation in COPD. Prim Care Respir J. 2013;22(1): 101-111.

13. Troosters T, Bourbeau J, Maltais F, et al. Enhancing exercise tolerance and physical activity in COPD with combined pharmacological and non-pharmacological interventions: PHYSACTO randomised, placebocontrolled study design. BMJ Open. 2016;6(4):e010106.

14. Beeh KM, Singh D, Di Scala L, Drollmann A. Once-daily NVA237 improves exercise tolerance from the first dose in patients with COPD: the GLOW3 trial. Int J Chron Obstruct Pulmon Dis. 2012;7:503-513.

15. Maltais F, Hamilton A, Marciniuk D, et al. Improvements in symptomlimited exercise performance over $8 \mathrm{~h}$ with once-daily tiotropium in patients with COPD. Chest. 2005;128(3):1168-1178.

16. Maltais F, Celli B, Casaburi R, et al. Aclidinium bromide improves exercise endurance and lung hyperinflation in patients with moderate to severe COPD. Respir Med. 2011;105(4):580-587.

17. O'Donnell DE, Casaburi R, Vincken W, et al. Effect of indacaterol on exercise endurance and lung hyperinflation in COPD. Respir Med. 2011;105(7):1030-1036. 
18. Beeh KM, Watz H, Puente-Maestu L, et al. Aclidinium improves exercise endurance, dyspnea, lung hyperinflation, and physical activity in patients with COPD: a randomized, placebo-controlled, crossover trial. BMC Pulm Med. 2014;14(1):209.

19. Watz H, Krippner F, Kirsten A, Magnussen H, Vogelmeier C. Indacaterol improves lung hyperinflation and physical activity in patients with moderate chronic obstructive pulmonary disease-a randomized, multicenter, double-blind, placebo-controlled study. BMC Pulm Med. 2014; $14: 158$.

20. Watz H, Mailänder C, Baier M, Kirsten A. Effects of indacaterol/ glycopyrronium (QVA149) on lung hyperinflation and physical activity in patients with moderate to severe COPD: a randomised, placebocontrolled, crossover study (The MOVE Study). BMC Pulm Med. 2016;16(1):95.

21. Troosters T, Sciurba FC, Decramer M, et al. Tiotropium in patients with moderate COPD naive to maintenance therapy: a randomised placebo-controlled trial. NPJ Prim Care Respir Med. 2014;24:14003.

22. Demeyer H, Louvaris Z, Frei A, et al. Physical activity is increased by a 12-week semiautomated telecoaching programme in patients with COPD: a multicentre randomised controlled trial. Thorax. 2017;72(5): 415-423.

23. Wanger J, Clausen JL, Coates A, et al. Standardisation of the measurement of lung volumes. Eur Respir J. 2005;26(3):511-522.

24. Coates AL, Peslin R, Rodenstein D, Stocks J. Measurement of lung volumes by plethysmography. Eur Respir J. 1997;10(6):1415-1427.

25. Miller MR, Hankinson J, Brusasco V, et al. Standardisation of spirometry. Eur Respir J. 2005;26(2):319-338.

26. Rabinovich RA, Louvaris Z, Raste Y, et al. Validity of physical activity monitors during daily life in patients with COPD. Eur Respir J. 2013; 42(5):1205-1215.

27. Gimeno-Santos E, Raste Y, Demeyer H; PROactive consortium, et al. The PROactive instruments to measure physical activity in patients with chronic obstructive pulmonary disease. Eur Respir J. 2015;46(4):988-1000.

28. Beeh KM, Korn S, Beier J, et al. Effect of QVA149 on lung volumes and exercise tolerance in COPD patients: the BRIGHT study. Respir Med. 2014;108(4):584-592.
29. O'Donnell DE, Casaburi R, Frith P, et al. Effects of combined tiotropium/ olodaterol on inspiratory capacity and exercise endurance in COPD. Eur Respir J. 2017;49(4):1601348.

30. Jones PW, Beeh KM, Chapman KR, Decramer M, Mahler DA, Wedzicha JA. Minimal clinically important differences in pharmacological trials. Am J Respir Crit Care Med. 2014;189(3):250-255.

31. Puente-Maestu L, Palange P, Casaburi R, et al. Use of exercise testing in the evaluation of interventional efficacy: an official ERS statement. Eur Respir J. 2016;47(2):429-460.

32. Moy ML, Collins RJ, Martinez CH, et al. An internet-mediated pedometer-based program improves health-related quality-of-life domains and daily step counts in COPD: a randomized controlled trial. Chest. 2015;148(1):128-137.

33. Mendoza L, Horta P, Espinoza J, et al. Pedometers to enhance physical activity in COPD: a randomised controlled trial. Eur Respir J. 2015; 45(2):347-354.

34. Bourbeau J, Lavoie KL, Sedeno M, et al. Behaviour-change intervention in a multicentre, randomised, placebo-controlled COPD study: methodological considerations and implementation. BMJ Open. 2016;6(4) e010109.

35. Demeyer H, Burtin C, Hornikx M, et al. The minimal important difference in physical activity in patients with COPD. PLoS One. 2016; 11(4):e0154587.

36. Santus P, Radovanovic D, Balzano G, et al. Improvements in lung diffusion capacity following pulmonary rehabilitation in COPD with and without ventilation inhomogeneity. Respiration. 2016;92(5): 295-307.

37. Santus P, Radovanovic D, Di Marco F, Raccanelli R, Valenti V, Centanni S. Faster reduction in hyperinflation and improvement in lung ventilation inhomogeneity promoted by aclidinium compared to glycopyrronium in severe stable COPD patients. A randomized crossover study. Pulm Pharmacol Ther. 2015;35:42-49.

38. Moy ML, Martinez CH, Kadri R, et al. Long-term effects of an internetmediated pedometer-based walking program for chronic obstructive pulmonary disease: randomized controlled trial. J Med Internet Res. 2016;18(8):e215. 


\section{Supplementary materials Inclusion and exclusion criteria}

Key inclusion criteria

For inclusion in the study, patients had to fulfil all of the following criteria:

- Males and non-pregnant, non-lactating females aged $\geq 40$ years.

- Patients with a clinical diagnosis of COPD according to Global initiative for chronic Obstructive Lung Disease guidelines 2014, with a post-bronchodilator forced expiratory volume in $1 \mathrm{~s}\left(\mathrm{FEV}_{1}\right) \geq 40 \%$ and $<80 \%$ of the predicted value and $\mathrm{FEV}_{1}$ /forced vital capacity $<70 \%$ at Visit 1.

- Functional residual capacity (FRC) measured by body plethysmography at Visit $1 \geq 120 \%$ of predicted value.

- Modified Medical Research Council dyspnea scale $\geq 2$ at Visit 1.

- Current or former cigarette smokers with a smoking history of at least 10 pack-years at Visit 1.

- Willing to participate in the telecoaching program and enhance their physical activity.

\section{Key exclusion criteria}

Any of the following was regarded as a criterion for exclusion from the study:

- History or current diagnosis of asthma.

- Any respiratory tract infection (including upper respiratory tract) or COPD exacerbation in the 6 weeks prior to Visit 1 or during the run-in period.

- Hospitalization for an acute COPD exacerbation within 3 months prior to Visit 1 or during the run-in period.

- Clinically significant respiratory conditions other than COPD.

- Use of long-term oxygen therapy ( $\geq 15 \mathrm{~h} /$ day).

- Oxygen saturation $\leq 85 \%$ during exercise testing at Visit 1, 2, or 3 prior to randomization.

- Body Mass Index $\geq 40 \mathrm{~kg} / \mathrm{m}^{2}$.

- Pulmonary rehabilitation during the study and/or within 3 months prior to Visit 1 or during the run-in period.

- Clinically significant cardiovascular conditions.

- Clinically relevant abnormalities in the results of blood pressure, electrocardiogram, or physical examination at Visit 1.
- Conditions other than COPD that may have contributed to dyspnea and exercise limitation or with contraindications to clinical exercise testing according to American Thoracic Society recommendations for Cardiopulmonary Exercise Testing.

- Patients who cycled $<2$ minutes or $>15$ minutes during the constant work rate exercise tests conducted at Visit 2 (run-in visit) or at Visit 3 even after adjustment of the work load.

Patients who had participated in previous trials involving aclidinium bromide $(\mathrm{AB})$ monotherapy or $\mathrm{AB} /$ formoterol fumarate (FF) were allowed to be included in the study.

\section{Details of statistical analyses}

Assuming a screening failure rate of $25 \%$ and a drop-out rate of $10 \%, 335$ patients were required to be screened to ensure 267 were randomized and 240 patients completed the study. Change from baseline in trough FRC and $\mathrm{FEV}_{1}$ at Week 4 of treatment was analyzed using analysis of covariance (ANCOVA) models, adjusted for age and baseline values as covariates, with treatment group, sex, and smoking status as fixed-effect factors. To explore the robustness of the ANCOVA model, a nonparametric Wilcoxon-MannWhitney test and the estimated asymptotic shift HodgesLehmann test were carried out once the trial was unblinded. In addition, an analysis of potential outliers and influential data was carried out through the interquartile range, studentized residuals, and Cook's distance. Change from baseline in inspiratory capacity, exercise endurance time, physical activity, and Daily PROactive Physical Activity in COPD questionnaire score at Weeks 4 and 8 were analyzed using a mixed model for repeated measures (MMRM), adjusted for age and baseline values as covariates with treatment group, sex, smoking status, visit, and treatment-by-visit interaction as fixed-effect factors. Percentage of inactive patients data and the effect of behavioral intervention were analyzed using a logistic random-effect model for repeated measures for inactive patients, with a cut-off of $<6,000$ steps per day, using the same adjustments and covariates as the MMRM analyses. 
Table SI IECs/IRBs consulted

\section{Name and address of IEC/IRB}

\section{Canada}

Hamilton Integrated Research Ethics Board, 293 Wellington Street North Suite 102, Hamilton, ON, Canada, L8L 8E7

Queen's University Health Sciences \& Affiliated Teaching Hospitals Research Ethics Board, Queen's University, Kingston, ON, Canada, K7L 3N6 Comité d'éthique de la recherche de l'Institut Universitaire de Cardiologie et de Pneumologie de Québec (IUCPQ), 2725, Chemin Ste-Foy Québec, QC, Canada, GIV 4G5

University of Saskatchewan Biomedical Research Ethics Board, University of Saskatchewan Box 5000 RPO University $1607-$ I I 0 Gymnasium Place

Saskatoon, SK, Canada, S7N 4J8

\section{Germany}

Central and Local Ethics Committee: Ethikkommission der Ärztekammer Schleswig-Holstein Bismarckallee 8-12, 23795 Bad Segeberg

Local Ethics Committee: Ethikkommission der Landesärztekammer Hessen Im Vogelsgesang 3, 60488 Frankfurt am Main

Local Ethics Committee: Ethikkommission der Ärztekammer Westfalen-Lippe und der Medizinischen, Fakultät der WWU Münster Gartenstr.

2।0-2।4, 48147 Münster

Local Ethics Committee: Ethikkommission der Ärztekammer Hamburg Weidestr. 122 b, 22083 Hamburg

Local Ethics Committee: Ethikkommission der Ärztekammer Nordrhein Tersteegenstraße 9, 40474 Düsseldorf

Local Ethics Committee: Ethikkommission der Friedrich-Schiller-Universität Jena Bachstraße 18, 07740 Jena

Local Ethics Committee: Ethikkommission der Bayerischen Landesärztekammer Mühlbaurstraße 16, 81677 München

Local Ethics Committee: Ethikkommission zur Beurteilung medizinischer Forschung am Menschen der Ärztekammer Niedersachsen Berliner Allee 20, 30175 Hannover

Local Ethics Committee: Ethikkommission der Albert-Ludwigs-Universität Freiburg Engelberger Str. 21, 79I06 Freiburg

Local Ethics Committee: Ethikkommission des Landes Berlin, Landesamt für Gesundheit und Soziales Fehrbelliner Platz I, 10707 Berlin

Hungary

Medical Research Council Ethics Committee for Clinical Pharmacology, H-I05I Budapest, Arany János, u. 6-8., Hungary

Spain

Central and Local Ethics Committee: Comité Ético de Investigación Clínica del Hospital Clínico U. de Valencia, Fundación INCLIVA c/ Menéndez Pelayo, 446010 Valencia, Spain

Local Ethics Committee: Comité Ético de Investigación Clínica de Cáceres, Secretaría del CEIC de Cáceres Hospital Ntra. Sra. de la Montaña - Avda. de España, 210004 Cáceres, Spain

Local Ethics Committee: Comité Ético de Investigación Clínica del Instituto de Ciencias Médicas, Secretaría del CElC - Instituto de Ciencias Médicas, C/ Poeta Quintana, 5603004 Alicante, Spain

Local Ethics Committee: Comité Ético de Investigación Clínica del Hospital U. La Paz, Secretaría Técnica del CEIC - Hospital Universitario La Paz Planta $8^{a}$ Hospital General - Paseo de la Castellana, 26I 28046 Madrid, Spain

Abbreviations: IEC, independent ethics committee; IRB, institutional review board.

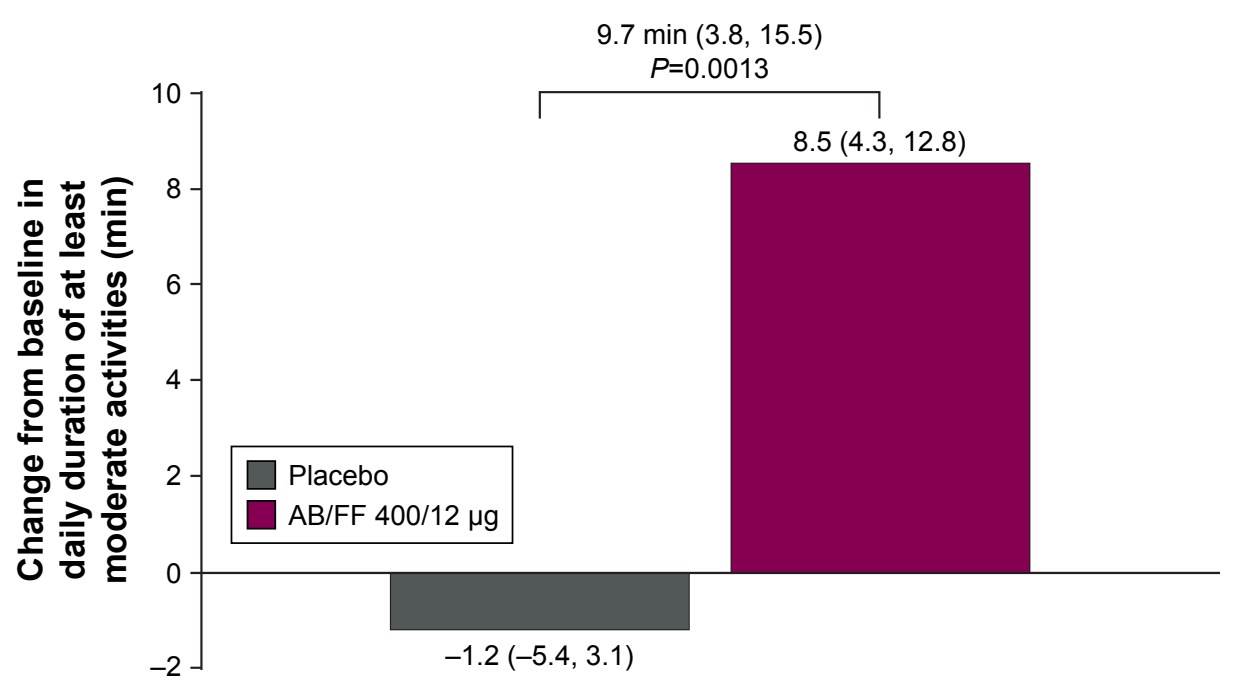

Figure SI Change from baseline in daily duration of at least moderate activities ${ }^{\mathrm{a}}$ at Week 4 (ITT population).

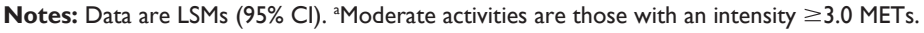

Abbreviations: $\mathrm{AB}$, aclidinium bromide; $\mathrm{Cl}$, confidence interval; FF, formoterol fumarate; ITT, intent-to-treat; LSM, least squares mean; MET, metabolic equivalents. 


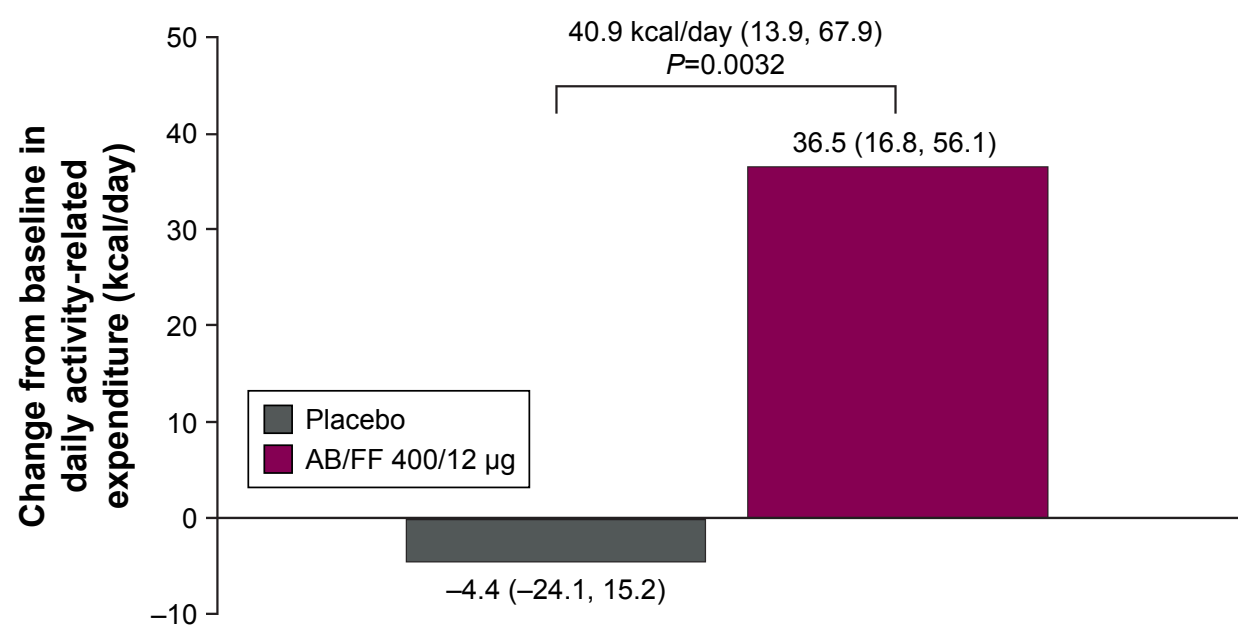

Figure S2 Change from baseline in activity-related energy expenditure at Week 4 (ITT population).

Note: Data are LSMs $(95 \% \mathrm{Cl})$.

Abbreviations: $\mathrm{AB}$, aclidinium bromide; $\mathrm{Cl}$, confidence interval; $\mathrm{FF}$, formoterol fumarate; ITT, intent-to-treat; LSM, least squares mean.

\section{Publish your work in this journal}

The International Journal of COPD is an international, peer-reviewed journal of therapeutics and pharmacology focusing on concise rapid reporting of clinical studies and reviews in COPD. Special focus is given to the pathophysiological processes underlying the disease, intervention programs, patient focused education, and self management protocols.
This journal is indexed on PubMed Central, MedLine and CAS. The manuscript management system is completely online and includes a very quick and fair peer-review system, which is all easy to use. Visit http://www.dovepress.com/testimonials.php to read real quotes from published authors. 